\title{
Liver injury induced by acipimox in a patient with hyperlipidemia: A first case report
}

\author{
gang qiu ${ }^{1}$, hongjian $\mathrm{ji}^{2}$, haojv $\mathrm{li}^{1}$, Xuefeng Zhang ${ }^{1}$, xiaodong ma ${ }^{1}$, and xiaohua $\mathrm{zhou}^{3}$ \\ ${ }^{1}$ Affiliation not available \\ ${ }^{2}$ Nanjing University of Chinese Medicine \\ ${ }^{3}$ Yancheng Third People's Hospital
}

September 28, 2020

\begin{abstract}
Acipimox, a niacin derivative, is a lipid-lowering drug that is widely used to treat hyperthyroidism. It is generally well tolerated and causes fewer adverse effects than niacin. Acipimox has been reported to induce mild adverse effects, mainly pruritus and flushing. Concerning hepatotoxicity induced by acipimox, only limited information is available regarding the symptoms and therapeutic schedule. In this study, we report the case of a 40-year-old man with hyperlipidemia who developed liver injury after treatment with acipimox. After treatment discontinuation, his liver function gradually improved. After obtaining negative results in tests for hepatitis, infectious mononucleosis, and rheumatologic diseases, in addition to ultrasonographic findings, acipimox administration was resumed, and his liver enzyme levels again remarkably increased. In the absence of any biliary obstruction or other obvious causes of hepatic injury, acipimox-induced hepatocellular injury was strongly suspected in accordance with the Roussel-Uclaf Causality Assessment Method. Acipimox was again discontinued, and magnesium isoglycyrrhizinate was introduced. The patient's liver function tests gradually improved over 3 days and displayed marked improvement after 1 week. On the basis of the recorded findings, drug-induced liver injury was highly suspected, and rechallenge and the exclusion of other obvious factors were required to establish the diagnosis of acipimox-induced hepatic injury. Furthermore, the importance of evaluating hepatotoxicity using the Roussel-Uclaf Causality Assessment Method and the effectiveness of magnesium isoglycyrrhizinate for treating liver cell injury were demonstrated.
\end{abstract}

\section{Keywords}

acipimox, liver injury, adverse drug reaction, magnesium isoglycyrrhizinate

\section{Introduction}

Epidemiological data have identified elevated low-density lipoprotein cholesterol levels as a common risk factor for cardiovascular disease. Niacin has usually been recommended to control lipid levels as monotherapy in patients intolerant to statins (1-4). However, a high incidence of niacin-induced adverse events such as pruritus, flushing, gastrointestinal disorders and hepatobiliary disorders has been reported (5). Because of its lower incidence of adverse events than niacin, acipimox is used to reduce lipid levels instead of nicotinic acid under most circumstances (6). However, acipimox-induced hepatotoxicity might be ignored by physicians or clinical pharmacists. In addition, it is difficult to manage drug-induced hepatotoxicity in some cases owing to the lack of valid clinical biomarkers and limited treatment methods.

This study reported a rare case of acipimox-induced hepatocellular injury in a patient with hyperlipidemia, and it represents the first reported case confirmed by a positive rechallenge test.

\section{RESULTS - CASE PRESENTATION}


A 40-year-old man was admitted to our hospital with complaints of nausea and lack of appetite. The patient was previously healthy, and he had no history of liver disease and no known drug allergies. He also denied alcohol use, smoking, or any illicit drug use. Regarding lipid levels, the patient's total cholesterol and triglyceride levels were 5.7 (normal, $<5.2 \mathrm{mmol} / \mathrm{L}$ ) and $8.5 \mathrm{mmol} / \mathrm{L}$ (normal, $<1.7 \mathrm{mmol} / \mathrm{L}$ ), respectively. Computed tomography revealed fatty liver, resulting in a diagnosis of hyperlipidemia caused by abnormal triglyceride levels. The patient started treatment with fluvastatin $(40 \mathrm{mg}$, quaque nocte, po). Several days later, his serum lipid levels were reexamined, but no major difference in total cholesterol and triglyceride levels was noted. Because of a lack of efficacy, the doctor switched his treatment to acipimox capsules (250 $\mathrm{mg}$, three times/day, po) as replacement therapy.

Three days later, he presented with fever and progressive fatigue. The patient's laboratory findings were as follows: aspartate aminotransferase (AST), $93 \mathrm{U} / \mathrm{L}$ (normal, 0-40 U/L); alanine transaminase (ALT), 336 $\mathrm{U} / \mathrm{L}$ (normal, 0-50 U/L); alkaline phosphatase (ALP), $112 \mathrm{U} / \mathrm{L}$ (normal, 45-125U/L); and total bilirubin, $14.5 \mathrm{mg} / \mathrm{dL}$ (including a direct bilirubin level of $2.4 \mathrm{mg} / \mathrm{dL}$ ). In response to the findings of elevated liver marker levels, acipimox treatment was discontinued.

Over the next 2 days, his liver enzyme levels decreased as follows: AST, $35 \mathrm{U} / \mathrm{L} ;$ ALT, $96 \mathrm{U} / \mathrm{L} ;$ ALP, 91 $\mathrm{U} / \mathrm{L}$ and total bilirubin, $15.2 \mu \mathrm{mol} / \mathrm{L}$.

Abdominal ultrasonography performed on day 9 of hospitalization revealed no abnormalities or stones in the gallbladder or common bile duct. The patient had experienced no recent changes in his medication, excluding fluvastatin.

Because the patient's condition was stable and acipimox- or fluvastatin-induced liver injury was suspected, acipimox $100 \mathrm{mg} /$ day was reintroduced on day 13. His liver enzyme levels then increased rapidly, peaking as follows: AST, $55 \mathrm{U} / \mathrm{L}$; ALT, $240 \mathrm{U} / \mathrm{L}$; ALP, $59 \mathrm{U} / \mathrm{L}$ and total bilirubin, $11.5 \mu \mathrm{mol} / \mathrm{L}$. Repeat abdominal Doppler ultrasonography was performed, revealing no evidence of stones and patent portal, splenic, and hepatic veins. Serologic inspections for acute viral hepatitis A, B, and C; infectious mononucleosis antinuclear antibody; and anti-smooth muscle actin antibody were negative. The results for tumor markers such as alpha-fetoprotein, carcinoembryonic antigen, and cancer antigen 19-9 were also negative.

In the absence of any mechanical obstruction in the common bile duct or other obvious causes of hepatic injury, acipimox-induced hepatocellular injury was suspected.

The patient subsequently did not undergo diagnostic liver biopsy because the invasive procedure would have resulted in discomfort. Acipimox was discontinued on day 14. The patient was treated with magnesium isoglycyrrhizinate (MgIg) $0.1 \mathrm{~g}$ daily after the Roussel-Uclaf Causality Assessment Method (RUCAM) was implemented. Subsequently, both his ALT and AST levels were improved. Three days later, his liver biochemistry profile started to improve gradually, including the following findings: AST 27 U/L; ALT 72 U/L; and total bilirubin $13.4 \mu \mathrm{mol} / \mathrm{L}$ (day 17). Figure 1 presents the patient's liver enzyme levels throughout hospitalization (days 1-17) and during follow-up. The final diagnosis was acipimox-induced hepatocellular injury. On day 18, the patient was released from hospital. The results of follow-up liver function tests conducted 1 week after discharge were normal.

\section{Discussion}

Lipid-lowering therapy is the current standard treatment for patients with hyperlipidemia or coronary heart disease.

Currently, statins are the first-line lipid-lowering therapies for reducing the risk of cardiovascular events in patients. Niacin and its analogs are useful alternatives for patients who are intolerant to statins or who experience an unsatisfactory curative effect.

Niacin, a broad-spectrum lipid-regulating agent, has been demonstrated to exert multiple favorable effects on cholesterol metabolism, including reductions of total cholesterol, triglyceride, very low-density lipoprotein, 
low-density lipoprotein cholesterol and lipoprotein levels and an augmentation of high-density lipoprotein cholesterol levels $(6,7)$.

Compared with several other commonly used lipid-altering drugs, including gemfibrozil, fenofibrate, simvastatin and atorvastatin, niacin is associated with lower rates of serious adverse events (defined as events resulting in hospitalization or death) and hepatotoxicity $(8,9)$. Unlike niacin, acipimox has not been reported to induce liver injury in clinical application (5).

In the traditional diagnostic approach for suspected drug-induced liver injury (DILI), which involves clinical, biochemical, and histological evaluations, attempts are made to establish the latency between the start of drug therapy and the onset of injury, clinical signatures, the exclusion of alternate etiologies and evidence of improvement of liver injury upon drug withdrawal (dechallenge). In fact, although the assessment of liver pathology through liver biopsy following treatment with the suspected cause is an important component of diagnostic criteria, this is often unethical to perform in practice.

Several diagnostic methods are applied clinically, such as expert opinion by experienced clinicians, RUCAM, the Maria and Victorino scale and the Naranjo scale. The opinions of clinicians can be problematic because of the inherently subjective nature of this approach. Meanwhile, the Naranjo scale was designed to assess all forms of adverse drug reactions. In this case, RUCAM has proven most accurate for diagnosing hepatotoxicity $(10,11)$.

Liver biopsy was not performed because of his rapid clinical and biochemical recovery, this procedure would have resulted in discomfort for our patient.

Our patient was retreated with acipimox in light of acipimox- or fluvastatin-induced liver injury was suspected, the patient's score of 9 of 14 on the RUCAM scale established a probable diagnostic relationship between acipimox exposure and hepatocellular injury.

Over the past several years, N-acetylcysteine has been used as a potential therapeutic approach for DILI $(12,13)$. It was proposed that $\mathrm{N}$-acetylcysteine could improve microcirculatory dysfunction and oxygen delivery in peripheral tissue beds by inducing an antioxidant effect and ameliorating the 'cytokine storm' (14). $\mathrm{N}$-acetylcysteine was in short supply because of the COVID-19 outbreak in China in March 2020. Clinicians and clinical pharmacists adopted MgIg instead of $\mathrm{N}$-acetylcysteine even though it was not mentioned in guidelines (13). Experiments revealed that MgIg was effective and safe in patients with acute DILI, possibly by reducing oxidant stress and modulating cyclooxygenase and 5-lipoxygenase pathways (16-18). Although MgIg was successfully used to treat DILI, large randomized controlled trials are needed to confirm its efficacy and safety. One limitation of this report is that liver biopsy was not performed before diagnostic procedures or after the administration of MgIg.

We encountered a case of hepatocellular injury induced by acipimox that was successfully treated with MgIg. Clinical features are important for determining the type of hepatitis, in addition to the results of rechallenge (e.g., considerable elevation of AST and ALT levels compared with the findings for biliary tract enzymes such as ALP and total bilirubin, which indicate liver cell injury). Excellent therapeutic results were obtained in our patient by discontinuing the suspected causative agent and applying MgIg. Our patient recovered during the follow-up period.

\section{4 conclusion}

In conclusion, acipimox is a well-tolerated lipid-lowering agent that has been increasingly recommended in recent years. Although routine liver function monitoring is not recommended for patients receiving acipimox because hepatotoxicity is rarely caused by the drug, a high degree of vigilance is required of clinicians to diagnose acipimox-induced hepatotoxicity. MgIg is a viable therapeutic option for DILI due to its cytoprotective and immunomodulatory effects.

\section{Acknowledgements}


We thank Joe Barber Jr., PhD, from Liwen Bianji, Edanz Editing China (www.liwenbianji.cn/ac), for editing the English text of a draft of this manuscript.

\section{Funding information}

This study was supported by the Medical and Health Research Project of Zhejiang Province (2018KY811) and Jiangsu Provincial Commission of Health and Family Planning, China (QNRC2016465).

\section{COMPETING INTERESTS}

There are no competing interests to declare.

\section{CONTRIBUTORS}

G.Qiu, H.J. Ji and X.F. Zhang helped to draft the manuscript and interpret the data. H.J. Li, X.H. Zhou and X.D.Ma helped to revise the article critically for important intellectual content.

\section{REFERENCES}

1.Elvira D'Andrea, Spencer P. Hey, Cherie L. Ramirez, et al. Assessment of the Role of Niacin in Managing Cardiovascular Disease Outcomes:A Systematic Review and Meta-analysis.JAMA Network Open . 2019,2(4):e192224.

2. Paul M.Lavigne, Richard H.Karas. The Current State of Niacin in Cardiovascular Disease Prevention: A Systematic Review and Meta-Regression. J Am Coll Cardiol .2013,61(4): 440-446.

3. R. Fogari, G. Marasi, A. Vanasia, A. Zoppi, P. Lusardi, et al. Comparative study of acipimox and pravastatin in patients with combined hyperlipidemia. Int J Clin Pharmacol Ther .1997,35(2):61-64.

4.Miroslav Zeman, Marek Vecka, František Perlík, Barbora Staňková, Robert Hromádka, Eva Tvrzická, Jakub Širc, Jakub Hrib, Aleš Žák. Pleiotropic effects of niacin: Current possibilities for its clinical use. Acta Pharmaceutica , 2016,66(4):449-469.

5.G Crepaldi, P Avogaro, G C Descovich, et al. Plasma lipid lowering activity of acipimox in patients with type II and type IV hyperlipoproteinemia. Results of a multicenter trial.Atherosclerosis , 1988, 70(1-2):115121.

6.Kamanna VS, Kashyap ML. Mechanism of action of niacin on lipoprotein metabolism. Curr Atheroscler Rep, $2000 ; 2: 36-46$.

7.Kamanna VS, Kashyap ML. Nicotinic acid (niacin) receptor agonists: will they be useful therapeutic agents? . J Am Coll Cardiol. 2007;100:S53-61.

8. The AIM-HIGH Investigators. Niacin in patients with low HDL cholesterol levels receiving intensive statin therapy .N Engl J Med 2011;365:2255-2267.

9.Alsheikh-Ali AA, Karas RH. The safety of niacin in the US Food and Drug Administration adverse event reporting database. Am J Gastroenterol, 2008,101:9B-13B.

10.Chalasani NP, Hayashi PH, Bonkovsky HL, et al. Clinical Guideline: the diagnosis and management of idiosyncratic drug-induced liver injury.Am J Gastroenterol 2014,109 (7) :950-966.

11.Don C. Rockey, Leonard B. Seeff, James Rochon, et al. Fontana, and Paul H. Hayashi, for the US DrugInduced Liver Injury Network. Causality Assessment in Drug-Induced Liver Injury Using a Structured Expert Opinion Process: Comparison to the Roussel-Uclaf Causality Assessment Method. Hepatology . 2010,51(6): $2117-2126$

12. Adrian Reuben, David G Koch, William M Lee, Acute Liver Failure Study Group Drug-induced acute liver failure: results of a U.S. multicenter, prospective study. Hepatology, 2010;52(6):2065-2076 
13. Michael F Vaezi, John E Pandolfino, Marcelo F Vela. ACG clinical guideline: diagnosis and management of achalasia. Am J Gastroenterol , 2013;108(8):1238-1249.

14. P Harrison, J Wendon, R Williams. Evidence of increased guanylate cyclase activation by acetylcysteine in fulminant hepatic failure. Hepatology, 1996,23(5):1067-1072.

15.The Study of Drug Induced Liver Disease of Chinese Medical Association. Diagnosis and treatment guideline on drug-induced liver injury. Chinese Journal of Hepatology ,2015,23(11):810-820.

16.Y.f. Wang, Z.h. Wang, M.q. Gao, et al. Efficacy and safety of magnesium isoglycyrrhizinate injection in patients with acute drug-induced liver injury: A phase II trial. Liver International . 2019,39(11):2102-2111.

17.Xie C, Li X, Wu J, et al. Anti-inflammatory activity of magnesium isoglycyrrhizinate through inhibition of phospholipase A2/arachidonic acid pathway.Inflammation . 2015;38(4):1639-1648.

18.Huang X, Qin J, Lu S. Magnesium isoglycyrrhizinate protects hepatic L02 cells from ischemia/reperfusion induced injury. Int J Clin Exp Pathol. 2014; 7(8): 4755- 4764.

\section{Hosted file}

FIGURE 1.pdf available at https://authorea.com/users/362429/articles/483581-liver-injuryinduced-by-acipimox-in-a-patient-with-hyperlipidemia-a-first-case-report 